\title{
Novel Applications of Nanotechnology in Life Sciences
}

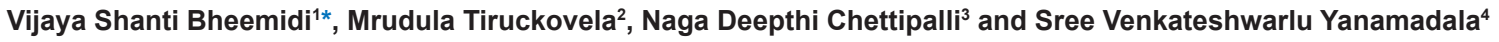

${ }^{1}$ Department of Biotechnology, Nottingham Trent University, Nottingham, United Kingdom

${ }^{2}$ Department of Biotechnology, Nottingham Trent University, Nottingham, United Kingdom

${ }^{3}$ Department of Microbiology, Andhra University, Andhra Pradesh, India

${ }^{4}$ Department of Biotechnology, DNR College, Andhra University, Andhra Pradesh, India

\begin{abstract}
The main focus of the review is to discuss about the most popular, expanding and promising branch of science and technology i.e., nanotechnology, its various applications in life sciences which opened up doors in several areas like diagnostics, drug delivery and tissue engineering. Nanotechnology is often viewed as a relatively young field, with tremendous potential to reinvent existing industries and significantly improve standards of living. Nanotechnology applications to the life sciences include pharmaceuticals, biotechnology, medical devices, diagnostics, gene therapy, drug delivery and tissue engineering.
\end{abstract}

Keywords: Nanoparticles; Drug delivery; Lab-on-a-chip; Tissue Engineering

\section{Introduction}

Nanotechnology is defined especially as growing and exciting technology at the scale of one-billionth of a metre sweeping away the barriers between the physics, chemistry and biology. Nanotechnology is the design, characterization, production and application of structures, devices and systems by controlling shape and size at nanometer scale $[1,2]$. There are two fundamental approaches at nanoscale: "Topdown" means the production of nanostructures materials by taking bulk material and forming it into desired structure which include development of integrated circuits (ICs). "Bottom-up" approach refers to building up nanostructures atom-by-atom or molecule-by-molecule i.e., quantum dots and nanotubes [3]. Nanotechnology word Originates from the Greek word meaning "dwarf", in science and technology the prefix "nano" signifies $10-9$, i.e. one billionth $(=0.000000001)$.One nanometre $(\mathrm{nm})$ is one billionth of a metre, tens of thousands of times smaller than the width of a human hair.

The nanotechnology platform was actually laid by Richard Feynman, a famous physicist gave this idea in his lecture given at California Institute of Technology called "there is plenty of room at the bottom", a belief of many workers in the field of nanotechnology. He presented a technological vision of miniaturization of materials, manipulating and controlling at nanoscale called "Nanotechnology" [4]. Feynman envisaged the technology to build nano-object, atomby-atom and molecule-by-molecule using tool box [5]. Nanoscale, nanotechnology, nanoengineering and nano-object became the modern concept of Feynman speech instead of the terms used such as small scale, small things and miniaturization [6]. Norio Taniguchi from Tokyo Science University first defined nanotechnology in 1974 as "Nano-technology mainly consists of the processing of separation, consolidation and deformation of materials by one atom or one molecule. Despite the hype around nanotechnology in recent years, it is not a new technology which include examples like Lycurgus glass cup in British Museum looks jade green in natural light and red colour when bright light shines through it due to nanoparticles of gold and silver [7], carbon nanoparticles are used in car tyres manufacturing while the red and yellow colours seen at sunsets are due to the nanoparticles in the atmosphere [8]. Some of the ancient examples include - nanotechnology used to make weapons and long lasting cave paintings about 2000 yrs ago by Indian craftsmen and artisans, existence of carbon nanoparticles on the famous sword of Tipu Sultan and Ajanta paintings. The first observation and size measurements of nanoparticles were carried out using an ultramicroscope by Richard Zsigmondy in 1902. The term "Nanotechnology" was first used by Norio Taniguchi, University of Tokyo to describe the ability to engineer materials at nanoscale [9]. In the 1980s, two inventions which enabled the imaging of individual atoms or molecules as well as their manipulation led to the significant progress in the field of nanotechnology [10]. In 1986, Eric Drexler recognized for driving the nanotechnology where it is today through his speeches and books "Engines of creation: the coming era of nanotechnology" and In 1991, Saumio lijima discovered carbon nanotubes and by 2000, the United States launched the National Nanotechnology Initiative (NNI-a federal visionary research \& development programme for nanotechnology) \& these paved way for the progress in research and development in the field of nanotechnology. A disruptive technology with a potential to change the world as we know it today [11].

\section{Impact on life sciences}

Nanotechnology is an emerging technology which is widely expected to provide technical solutions and economically successful products in various fields of application [11]. Already in the market the nanotechnology products available but still it is very intensive basic research field. In other words discovery in nanotechnology implies increasingly impact on life sciences [12]. It refers to a set of technologies that are being applied to numerous existing industries has mainly three overlapping areas such as Nanoelectronics, nanomaterials, nanobiotechnology which find applications in various fields like electronics, materials, environment, metrology, robotics, healthcare, information technology, pharmaceutics, agriculture, transport etc [1315]. Nanotechnology is often viewed as a relatively young field, with

*Corresponding author: Vijaya Shanti Bheemidi, Department of Biotechnology, Nottingham Trent University, Nottingham, United Kingdom, E-mail: shantu_59@ yahoo.com

Received June 01, 2011; Accepted July 10, 2011; Published July 13, 2011

Citation: Vijaya Shanti B, Mrudula T,Naga Deepth $\mathrm{CH}$, Sree VenkateshwarluY (2011) Novel Applications of Nanotechnology in Life Sciences. J Bioanal Biomed S11. doi:10.4172/1948-593X.S11-001

Copyright: (C 2011 Vijaya Shanti B, et al. This is an open-access article distributed under the terms of the Creative Commons Attribution License, which permits unrestricted use, distribution, and reproduction in any medium, provided the original author and source are credited. 
Citation: Vijaya Shanti B, Mrudula T,Naga Deepth CH, Sree VenkateshwarluY (2011) Novel Applications of Nanotechnology in Life Sciences. J Bioanal Biomed S11. doi:10.4172/1948-593X.S11-001

tremendous potential to reinvent existing industries and significantly improve standards of living. Nanotechnology applications to the life sciences include pharmaceuticals, biotechnology, medical devices, diagnostics, gene therapy, drug delivery and tissue engineering [16-20] (Figure 1).

\section{Nanotechnology-drug delivery}

There are many potentially valuable prospects in nanotechnology for drug delivery systems. Some of the advantageous areas in which nanotechnology efforts are being made include vaccine adjuvants and delivery systems, nanostructured applications used in orthopaedics and wound management [21-23], controlled release drug delivery system, delivery vehicles that enhance circulation and targets of drug and to specific cells, systems that improve the solubility of poorly water soluble drugs [24-27]. Some types of nanotechnologies being utilized in drug delivery as follows:

\section{Polymer nanoparticles}

Polymer drug conjugates are used as drug delivery sytems as many pharmaceuticals are not soluble in water, inefficiency towards specific target site. Some of the examples include PEGylated liposomal nanoparticle formulation of GMP-grade WHI-P131 exhibited potent in vivo activity shows therapeutic potential against breast cancer than chemotherapy drugs like paclitaxel, gemcitabine [28].

\section{Quantom dots}

Flouroscent invisible nanocrystals measuring around 2-10nm smaller than the wavelength of visible light made to fluorescence stimulated by light have range of health applications for tracing the course of therapeutic drugs or establishing circulatory problems in the human body. Example include chitosan (N-(2- hydroxyl) propyl3-trimethyl ammonium chitosan chloride, HTCC/CdS quantum nanodots can be potentially used in biological applications and labelling of biomolecules [29].

\section{Vaccines}

Number of systems have been developed which can be used as an alternative alternative to traditional biological vaccine methods. Of which nanovectors developed for influenza is one of the example.
These systems proved to be very successful as nanovectors are used to trigger the body's immune system [30].

\section{Nano-fabricated structures}

Emerging field where nanofabricated surface structures are used as peremeable layers so that they don't allow unnecessary molecules to pass through it [31].

\section{Nanotechnology-diagnostic applications}

The recent developing and revolutionary area of nanotechnology is molecular diagnostics which requires small amount of sample, less time, quick process and reliable for different kinds of analysis [3234]. By using lab-on-chip technology we can synthesize small chip analyzer used to analyze the samples within few minutes then and there itself instead of sending them to laboratory for analysis purposes [35]. Companies are working harder to synthesize new chip analyzersrequire only nanogram or picolitre sized samples which gives more scope for efficient analysis and reliability [36-41]. There are different lab-on-a-chip devices already available in the market for analytical purposes. Eg: "Gluco-watch" which permeates your skin with fluidic nanochip biosensors that sense the level of blood Lab-on-a-chip technology is the basis for combinatorial screening techniques, which, when combined with powerful computers can dramatically speed up the new drug discovery process [42-45].

\section{Tissue engineering}

Tissue engineering is the interface between pharmaceutical and biomedical industry where nanotechnology will have real impact. In developed countries, this field growing rapidly in terms of commercial importance day-by-day [46-50]. Some of the examples include internal tissue implants- shortfall in providing replacement organs lead to xenotransplants, so nanotechnology can be used to grow tissues \& organs artificially on nanopatterned scaffolds, Medical devices include contact lenses require surface topography measurement at the nanolevel to verify shape and intended optical profiles using nanostructured materials and functionalized surfaces [51], Nanorobot therapeuticsthe speculative area which may take atleast 20years and in future it's been envisaged that nanorobots will float around the body and carry out targeted healing jobs [52], In-vivo testing devices-these include

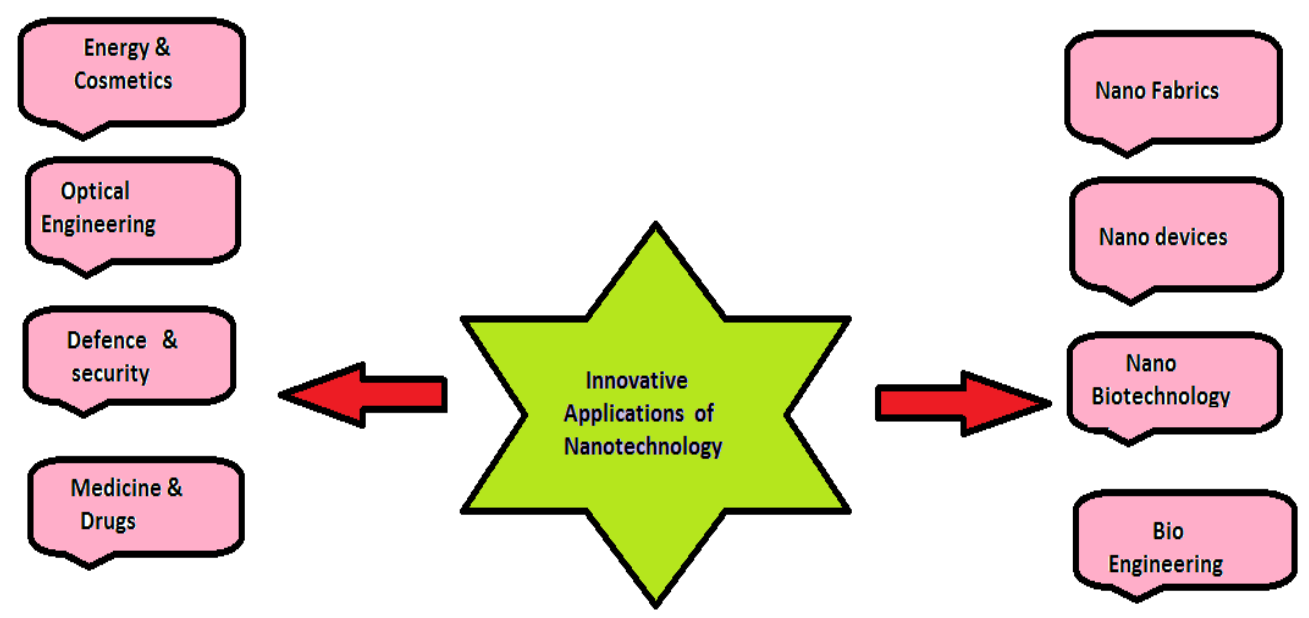

Figure 1: Innovative applications of nanotechnology. 
Citation: Vijaya Shanti B, Mrudula T,Naga Deepth CH, Sree VenkateshwarluY (2011) Novel Applications of Nanotechnology in Life Sciences. J Bioanal Biomed S11. doi:10.4172/1948-593X.S11-001

Page 3 of 4

the devices or sensors which can be used to detect cancer, infections and coronary heart attacks etc and small transmitters are used to communicate with outside world and tell patient is at particular risk at that moment in time. Miniaturisation is the key to these applications, combining sensors and actuators with nanoscale features to produce personal health devices [53].

\section{Benefits and risks of nanotechnology}

Due to broad spectrum of nanotechnology applications, it has numerous benefits in both developed and developing countries like improvement on transport systems, cheaper and clean energy, clean drinking water due to nanofilters that can entrap organisms and toxins, improved healthcare system by fabrication of devices and drug delivery systems for diagnosis, monitoring and treatment of dreadful diseases, clean environment by removal of pollutants through remediation, creation of new products and improvement of existing products at nanosacle etc which paves the industrial revolution that may change every aspect of human life [53]. Inspite of the potential applications of nanotechnology, it has some risks include nanoparticles such as copper, cobalt etc have inflammatory and toxic effects on human cells [54] , chemical weapons fabricated from nanoparticles are more deadly than the present ones used in military, carbon nanotubes - cytotoxic in nature induce granulomas in lungs of laboratory animals [55]. Due to enormous applications and benefits of nanotechnology in various fields, ethical, social and safety studies should indicate how to maximize the benefits and reduce the risks.

\section{Future Prospectives and Conclusion}

Different aspects of nanotechnology brings the science almost incomprehensibly small device close and closer to reality and at some point developments will be so vast that they will affect all fields of science and technology. Although expectations are too high but safety of nanomedicine is not yet fully defined. Over the next coming years, it is predicted that nanotechnology going to evolve and expand in different fields of life sciences and its achievements being applied in medicine like diagnostics, tissue engineering and patient improvement which play crucial role in treatment of human diseases and also in improving human physiology.

\section{References}

1. Stylios GK, Giannoudis PV, Wan T (2005) Applications of nanotechnologies in medical practice. Injury 36: 1-6.

2. The Royal Society and the Royal Academy of Engineering. Nanoscience and Nanotechnologies. The Royal Society and the Royal Academy of Engineering Report, July 2004.

3. Majumder DD, Banerjee R, Ulrichs CH, Mewis I (2007) Nano-materials: Science of bottom-up and topdown. IETE Tech Rev 24: 9-25.

4. Sahoo SK, Parveen S, Panda JJ (2007) The present and future of nanotechnology in human health care. Nanomedicine: NBM 3: 20-31.

5. Nelson AO, Patrick OO, Ndidi CN (2009) Nanotechnology \& Drug Delivery Part 1: Background and applications. Tropical journal of pharmaceutical research 8 : 265-274

6. Feynman RP (1960) There is plenty of room at the bottom. California Institute of Technology $\mathrm{J}$ Eng Sci 4: 23-36.

7. Smith A (2006) Nanotechnology: lessons from Mother Nature. Chemistry International 28: 10-11.

8. Smith A (2006) Nanotechnology: Does it have a sporting chance. Chemistry International 28: 8-9.

9. Miyazaki K, Islam N (2007) Nanotechnology systems of innovation - An analysis of industry and academia research activities. Technovation 27: 661671.
10. Cortie MB (2004) The weird world of nanoscale gold. Gold Bulletin 37: 12-19.

11. Verma S, Domb AJ, Kumar N (2011) Nanomaterials for regenerative medicine. Nanomedicine (Lond) 6: 157-181.

12. Matija L (2004) Reviewing paper: Nanotechnology: Artificial versus natural selfassembly. Fac Mech Eng (FME) Trans 32: 1-14.

13. Dibirdik I, Yiv S, Qazi S, Uckun FM (2010) In vivo Anti-Cancer Activity of a Liposomal Nanoparticle Construct of Multifunctional Tyrosine Kinase Inhibitor 4-(4'-Hydroxyphenyl)-Amino-6,7-Dimethoxyquinazoline. J Nanomedic Nanotechnolo 1: 101.

14. Mehrotra A, Nagarwal RC, Pandit JK (2010) Fabrication of Lomustine Loaded Chitosan Nanoparticles by Spray Drying and in Vitro Cytostatic Activity on Human Lung Cancer Cell Line L132. J Nanomedic Nanotechnolo 1: 103.

15. Lukianova-Hleb EY, Oginsky AO, Shenefelt DL, Drezek RA, Hafner JH, et al. (2011) Rainbow Plasmonic Nanobubbles: Synergistic Activation of Gold Nanoparticle Clusters. J Nanomedic Nanotechnol 2: 104

16. Nakamura J, Nakajima N, Matsumura K, Hyon SH (2011) In Vivo Cance Targeting of Water-Soluble Taxol by Folic Acid Immobilization. J Nanomedic Nanotechnol 2: 106.

17. Nanjwade BK, Derkar GK, Bechra HM, Nanjwade VK, Manvi FV (2011) Design and Characterization of Nanocrystals of Lovastatin for Solubility and Dissolution Enhancement. J Nanomedic Nanotechnol 2: 107.

18. Pandurangappa C, Lakshminarasappa BN (2011) Optical absorption and Photoluminescence studies in Gamma-irradiated nanocrystalline $\mathrm{CaF}_{2}$. J Nanomedic Nanotechnol 2:108

19. Elgindy N, Elkhodairy K, Molokhia A, ElZoghby A (2011) Biopolymeric Nanoparticles for Oral Protein Delivery: Design and In Vitro Evaluation. J Nanomedic Nanotechnol 2:110.

20. Patil A, Chirmade UN, Slipper I, Lamprou DA, Urquhart A, et al. (2011) Encapsulation of Water Insoluble Drugs in Mesoporous Silica Nanoparticles using Supercritical Carbon Dioxide. J Nanomedic Nanotechnol 2:111.

21. Nimesh S, Manchanda R, Kumar R, Saxena A, Chaudhary P, et al. (2006) Preparation, characterization and in vitro drug release studies of nove polymeric nanoparticles. Int J Pharm 323: 146-152.

22. Soppimath K, Aminabhavi TM, Kulkarni AR, Rudzinski WE (2001) Biodegradable polymeric nanoparticles as drug delivery devices. J Controlled Release 70: 1-20.

23. Jung T, Kamm W, Breitenbach A, Kaiserling E, Xiao JX, et al. (2000) Biodegradable nanoparticles for oral delivery of peptides: is there a role for polymers to affect mucosal uptake? Eur J Pharm Biopharm 50: 147-160.

24. Thomas S, Waterman P, Chen S, Marinelli B, Seaman M, et al. (2011) Development of Secreted Protein and Acidic and Rich in Cysteine (SPARC) Targeted Nanoparticles for the Prognostic Molecular Imaging of Metastatic Prostate Cancer. J Nanomedic Nanotechnol 2: 112.

25. Salim N, Basri M, Rahman MB, Abdullah DK, Basri H, et al. (2011) Phase Behaviour, Formation and Characterization of Palm-Based Esters Nanoemulsion Formulation containing Ibuprofen. J Nanomedic Nanotechnol 2 113

26. Saboktakin MR, Tabatabaie RM, Maharramov A, Ramazanov MA (2011) Synthesis and Characterization of Biodegradable Thiolated Chitosan Nanoparticles as Targeted Drug Delivery System. J Nanomedic Nanotechno S4: 001.

27. Anwunobi AP, Emeje MO (2011) Recent Application of Natural Polymers in Nanodrug Delivery. J Nanomedic Nanotechnol S4: 002

28. Dibirdik I, Yiv S, Qazi S, Uckun FM (2010) In vivo Anti-Cancer Activity of a Liposomal Nanoparticle Construct of Multifunctional Tyrosine Kinase Inhibitor 4-(4'-Hydroxyphenyl)-Amino-6,7-Dimethoxyquinazoline. J Nanomedic Nanotechnolo 1: 101.

29. Knight LC, Romano JE, Krynska B, Faro S, Mohamed FB, et al. (2010) Binding and Internalization of Iron Oxide Nanoparticles Targeted To Nuclear Oncoprotein. J Mol Biomark Diagn 1: 102.

30. Lobo AO, Marciano FR, Regiani I, Matsushima JT, Ramos SC, et al. (2011) Influence of Temperature and Time For Direct Hydroxyapatite Electrodeposition on Superhydrophilic Vertically Aligned Carbon Nanotube Films. J Nanomedic Nanotechnol S8: 001. 
Citation: Vijaya Shanti B, Mrudula T,Naga Deepth CH, Sree VenkateshwarluY (2011) Novel Applications of Nanotechnology in Life Sciences. J Bioanal Biomed S11. doi:10.4172/1948-593X.S11-001

31. Mehrotra A, Nagarwal RC, Pandit JK (2010) Fabrication of Lomustine Loaded Chitosan Nanoparticles by Spray Drying and in Vitro Cytostatic Activity on Human Lung Cancer Cell Line L132. J Nanomedic Nanotechnolo 1: 103.

32. Havele S, Dhaneshwar S (2010) Estimation of Metformin in Bulk Drug and in Formulation by HPTLC. J Nanomedic Nanotechnolo 1: 102.

33. Eshita Y, Higashihara J, Onishi M, Mizuno M, Yoshida J, et al. (2011) Mechanism of the Introduction of Exogenous Genes into Cultured Cells Using DEAE-Dextran-MMA Graft Copolymer as a Non-Viral Gene Carrier. II. Its Thixotropy Property. J Nanomedic Nanotechnol 2: 105.

34. Lost RM, da Silva WC, Madurro JM, Madurro AG, Ferreira LF (2011) Recent advances in nano-based electrochemical biosensors: application in diagnosis and monitoring of diseases. Front Biosci (Elite Ed) 3: 663-689.

35. Mizuno K, Zhiyentayev T, Huang L, Khalil S, Nasim F, et al. (2011) Antimicrobia Photodynamic Therapy with Functionalized Fullerenes: Quantitative Structureactivity Relationships. J Nanomedic Nanotechnol 2: 109.

36. Cordell GA (2011) Sustainable medicines and global health care. Planta Med 77: 1129-1138

37. Elgindy N, Elkhodairy K, Molokhia A, ElZoghby A (2011) Biopolymeric Nanoparticles for Oral Protein Delivery: Design and In Vitro Evaluation. J Nanomedic Nanotechnol 2: 110.

38. Szebeni J (2011) Nanomedicine: application of nanotechnology in medicine Opportunities in neuropsychiatry. Neuropsychopharmacol Hung. 13: 15-24

39. Pandey RR, Saini KK, Dhayal M (2010) Using Nano-Arrayed Structures in SolGel Derived $\mathrm{Mn}^{2+}$ Doped $\mathrm{TiO}_{2}$ for High Sensitivity Urea Biosensor. Journal of Biosensors \& Bioelectronics 1: 1-4.

40. Verma N, Kumar S, Kaur H (2010) Fiber Optic Biosensor for the Detection of Cd in Milk. J Biosens Bioelectron 1: 102.

41. Sarvestani AS (2011) On the Effect of Substrate Compliance on Cellular Motility. J Biosens Bioelectron 2: 103.

42. Tateishi A, Cauchi M, Tanoue C, Migita S, Coleman SK, et al. (2011) Discerning Data Analysis Methods to Clarify Agonistic/Antagonistic Actions on the Ion Flux Assay of Ligand-Gated Ionotropic Glutamate Receptor on Engineered PostSynapse Model Cells. J Biosens Bioelectron 2: 104.
43. Li Y, Hu M, Qi B, Wang X, Du Y (2011) Preparation and Characterization of Biocompatible Quaternized Chitosan Nanoparticles Encapsulating CdS Quantum Dots. J Biotechnol Biomaterial 1: 108.

44. Abu Shawish HM, Al-Dalou AR, Abu Ghalwa N, Abou Assi AA (2010) Potentiometric Sensor for Determination of Tramadol Hydrochloride in Pharmaceutical Preparations and Biological Fluids. Pharm Anal Acta 1: 103

45. Rosarin FS, Mirunalini S (2011) Nobel Metallic Nanoparticles with Nove Biomedical Properties. J Bioanal Biomed 3: 085-091.

46. Rippel RA, Seifalian AM (2011) Gold revolution--gold nanoparticles for modern medicine and surgery. J Nanosci Nanotechnol 11: 3740-3748.

47. Kim KS, Khang G, Lee D (2011) Application of Nanomedicine in Cardiovascular Diseases and Stroke. Curr Pharm Des

48. Shih MF, Wu CH, Cherng JY (2011) Bioeffects of Transient and LowIntensity Ultrasound on Nanoparticles for a Safe and Efficient DNA Delivery. $J$ Nanomedic Nanotechnol.

49. Rakowska PD, Ryadnov MG (2011) Nano-enabled biomarker discovery and detection. Biomark Med 5: 387-396.

50. Boulaiz H, Alvarez PJ, Ramirez A, Marchal JA, Prados J, et al. (2011) Nanomedicine: application areas and development prospects. Int J Mol Sci 12 3303-3321.

51. Ambrogio MW, Thomas CR, Zhao YL, Zink JI, Stoddart JF (2011) Mechanized Silica Nanoparticles: A New Frontier in Theranostic Nanomedicine. Acc Chem Res

52. Dunphy Guzman KA, Taylor MR, Banfield JF (2006) Environmental risks of nanotechnology: National nanotechnology initiative funding, 2000-2004. Environ Sci Technol 40: 1401-1407.

53. Cobb MD, Macoubrice J (2004) Public perceptions about nanotechnology: risks, benefits and trust. J Nanoparticle Res 6: 395-405.

54. Roco MC (2003) Broader societal issues of nanotechnology. J Nanoparticle Res 5: 181-189

55. Oberdörster G, Oberdörster E, Oberdörster J (2005) Nanotoxicology: an emerging discipline evolving from studies of ultrafine particles. Env Health Perspectives 111: 823-839 